\title{
2017 Status Report - DOE Research Reactor Infrastructure Program
}

\author{
Douglas Morrell
}

September 2017

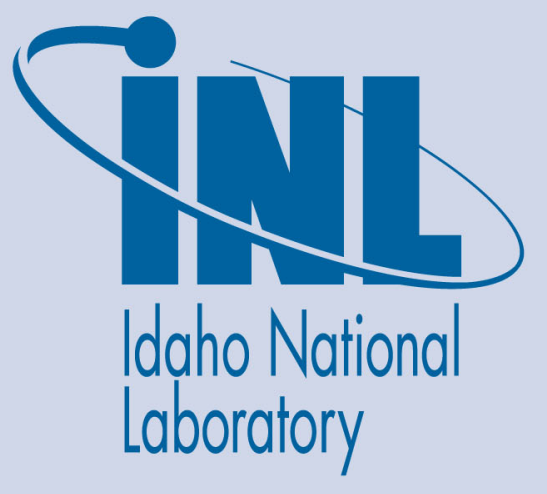

The INL is a U.S. Department of Energy National Laboratory operated by Battelle Energy Alliance 


\title{
2017 Status Report - DOE Research Reactor Infrastructure Program
}

\author{
Douglas Morrell
}

September 2017

Idaho National Laboratory Idaho Falls, Idaho 83415

http://www.inl.gov

Prepared for the

U.S. Department of Energy

Under DOE Idaho Operations Office

Contract DE-AC07-05ID14517 


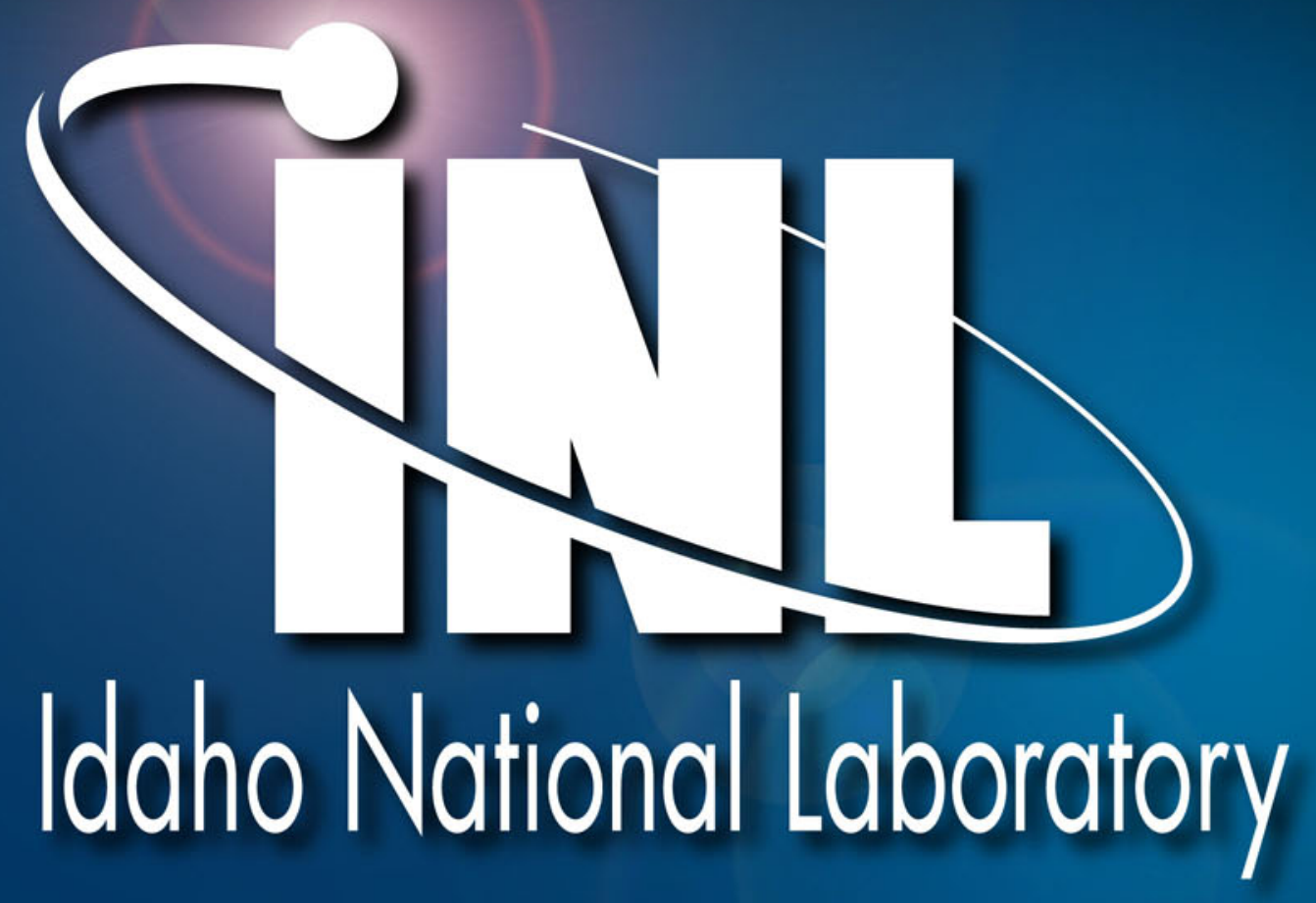




\section{Status Report}

\section{DOE Research Reactor Infrastructure Program}

Douglas Morrell

September 18, 2017 


\section{$\underline{\text { Topics for Discussion }}$}

- Overview of the Research Reactor Infrastructure Program

- Accomplishments during the past year

- 2018 Forecast

- Future Challenges

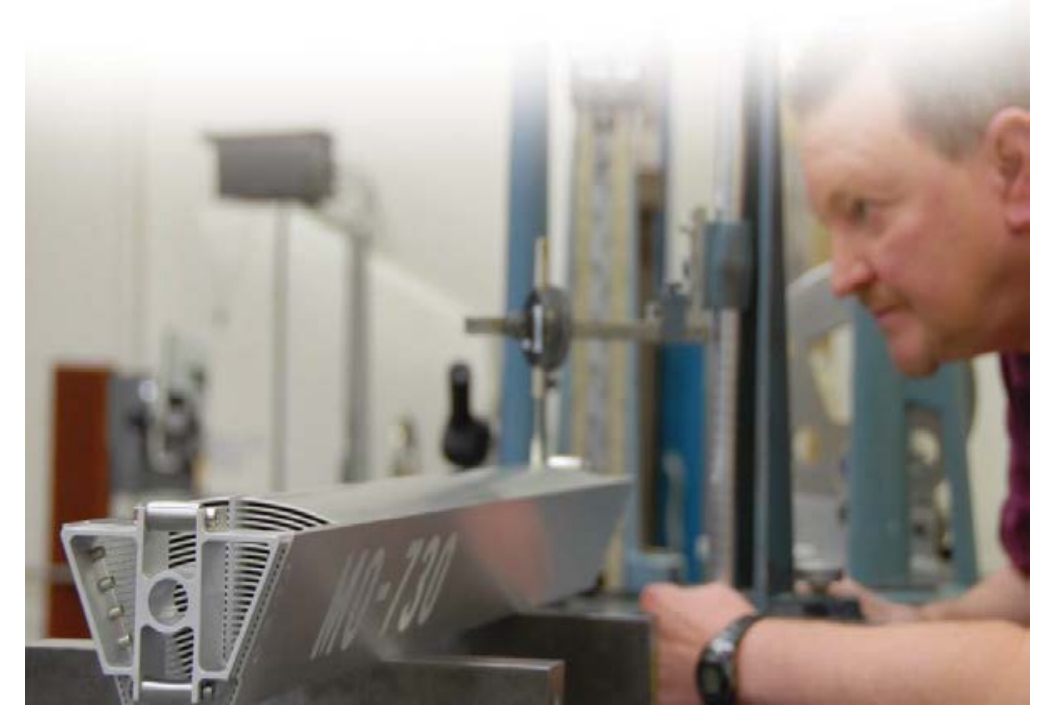




\section{Purpose of the RRI Program}

The purpose of the United State Domestic Research Reactor Infrastructure Program is to provide fresh nuclear reactor fuel to United States universities at no, or low, cost to the university. The title of the fuel remains with the United States government and when universities are finished with the fuel, the fuel is returned to the United States government.

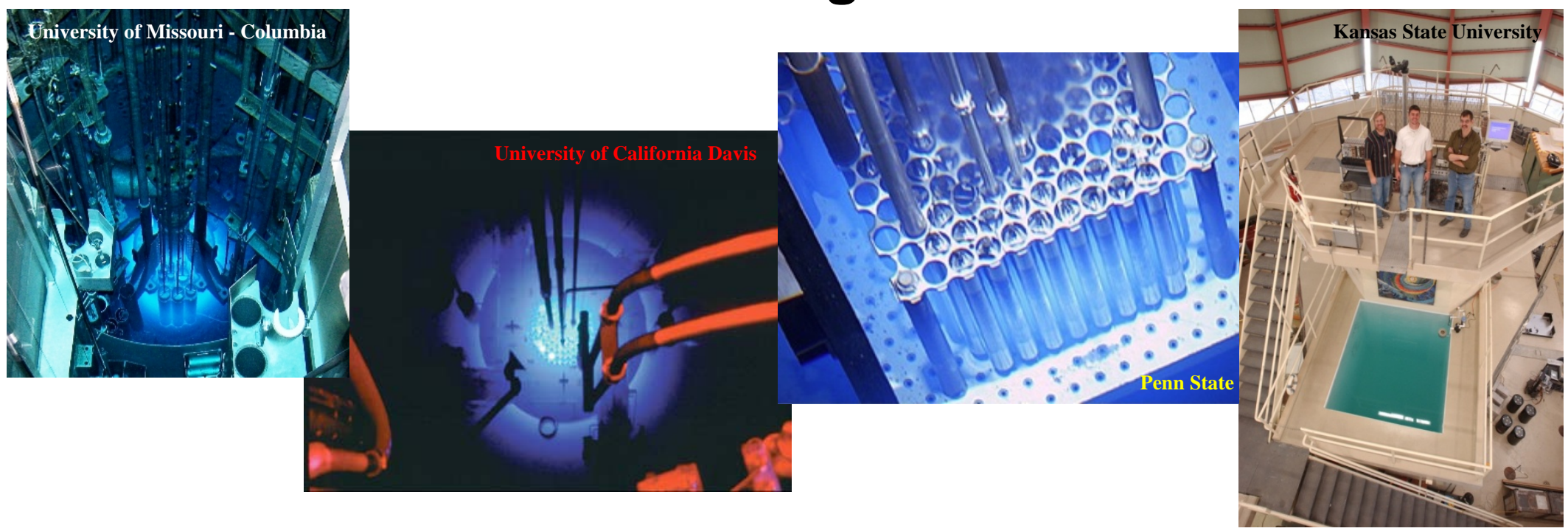




\section{Program Management}

DOE HQ

Idaho National Laboratory

Project Manager

Quality Engineer - in Idaho

Quality Engineer - in Virginia

Nuclear Materials Management

Subcontract Administration
Kenny Osborne

Won Yoon

Derick Ogg

Doug Morrell

Dana Cooper

Dave Capp

Michelle Wilkinson

Elise Miller 


\section{Points of Contact}

Points of Contact Organization

Doug Morrell

Dana Cooper

Dave Capp

Michelle Wilkinson

Elise Miller
INL

INL

INL

INL

INL
E-Mail Address

douglas.morrell@inl.gov

clinton.cooper@inl.gov

dfcapp@babcock.com

d.wilkinson@inl.gov

elise.miller@inl.gov
Phone Number

(208) 526-5876

(208) 526-3668

(434) 522-6545

(208) 526-3322

(208) 526-2196 


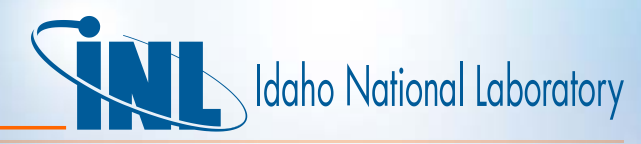

\section{Operating University Reactor Facilities}

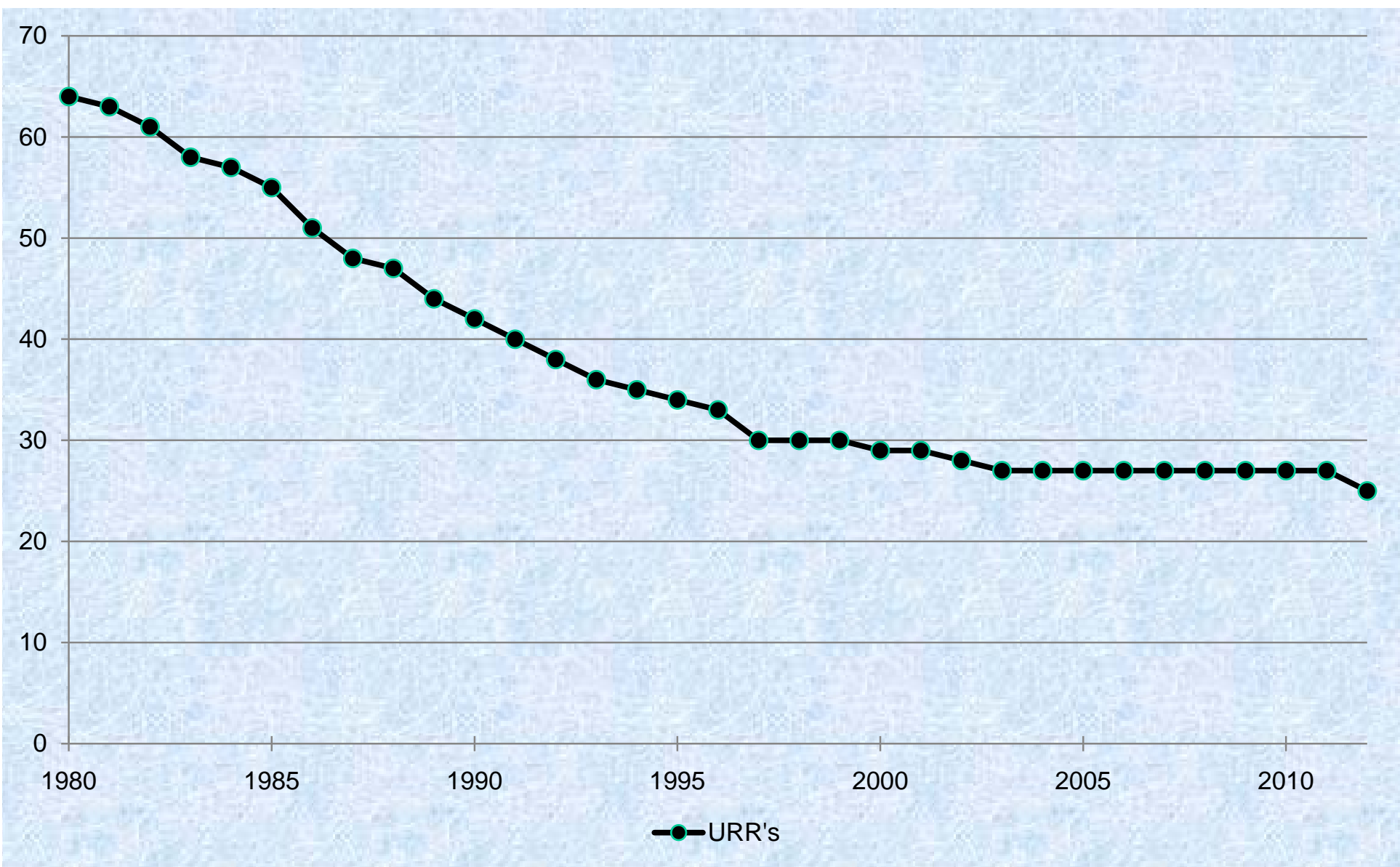




\section{The Research Reactor Infrastructure Program}

- Funded by the U.S. Department of Energy

- Managed by DOE-ID Operations Office

- Contracted to the INL's Management and Operations Contractor Battelle Energy Alliance

- Program has been at Idaho since 1977

- INL subcontracts with 24 U.S. universities to supply fresh nuclear reactor fuel for operations

- Twelve TRIGA facilities

- Eight plate fuel facilities

- Three AGN facilities

- One Pulstar fuel facility

- One Critical facility

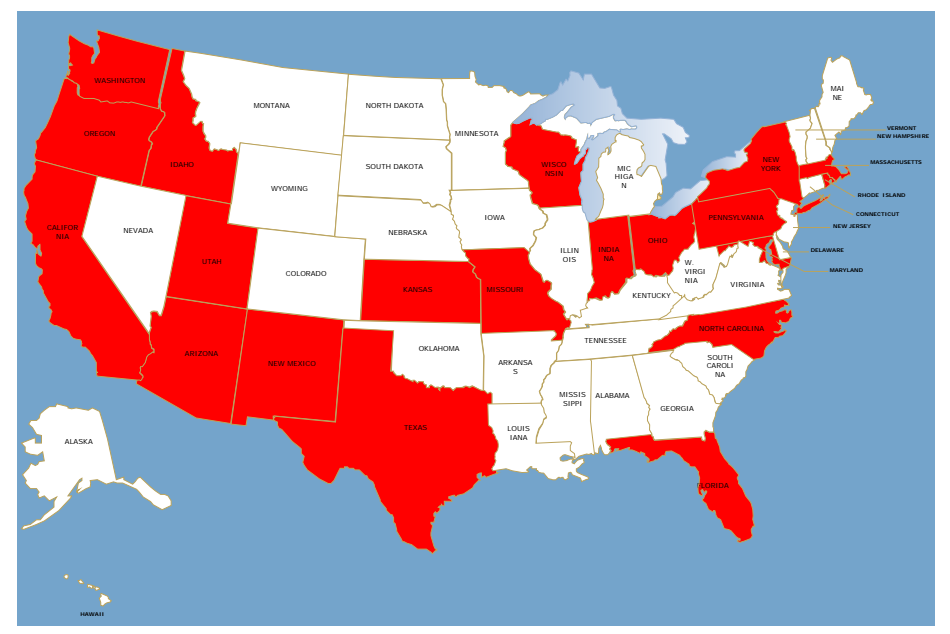


University TRIGA Reactor Facilities

THE

UNIVERSITY

OF UTAH

$\underline{\text { KANSAS STATE }} \mid$\begin{tabular}{l} 
TRIGA Mk II Nuclear \\
\hline U N I V E R S I T Y Yeactor Laboratory
\end{tabular}
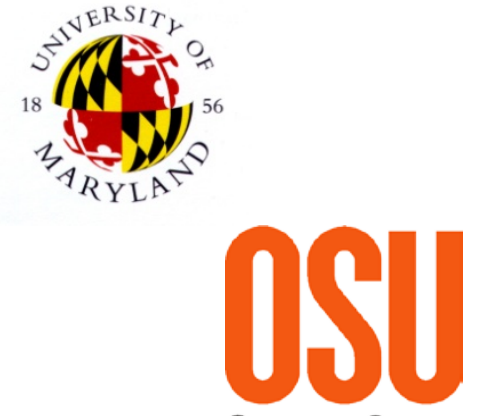

Oregon State

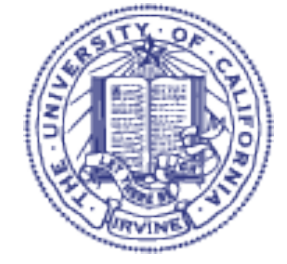

REED COLIEGE
- Kansas State University

- Oregon State University

- Penn State University

- Reed College

- Texas A\&M

- University of California Davis

- University of California at Irvine

- University of Maryland

- University of Texas at Austin

- University of Utah

- University of Wisconsin

- Washington State University

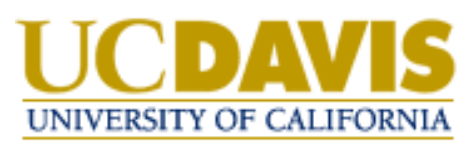

WASHINGTON STATE

UNIVERSITY

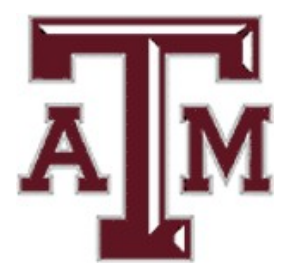




\section{TWL Idaho National laboratory}

University Plate Fuel Reactor Facilities

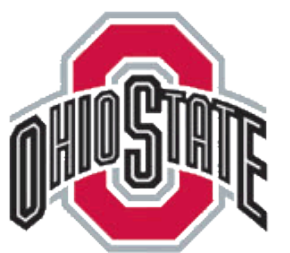

- Massachusetts Institute of Technology

- Missouri University of S\&T - Rolla

- Ohio State University

- Purdue University

- Rhode Island Nuclear Science Center

- University of Florida

PURDUE

- University of Massachusetts - Lowell

- University of Missouri - Columbia

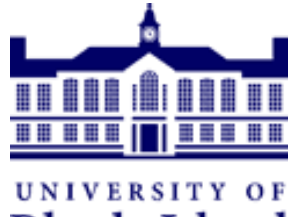

Rhode Island

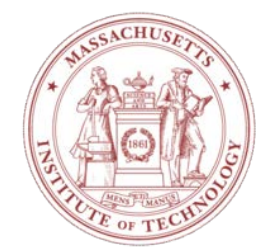

UF| $\left.\right|_{\text {FLORIVRITI }} ^{\text {ULA }}$ The Foundation for The Gator Nation

University of Missouri-Columbia 


\section{Other University Reactor Facilities}

- AGN Reactors

- Idaho State University

- Texas A\&M

- University of New Mexico

- Pulstar Reactor

- North Carolina State University

- Critical Facility

NC STATE UNIVERSITY

- Rennselaer Polytechnic Institute

(ii) Rensselaer 


\section{Reactor Power Levels}

\section{Facility}

University of Missouri - Columbia

Massachusetts Institute of Technology

University of California - Davis

Rhode Island Nuclear Science Center

Kansas State University

Oregon State University

University of Texas, Austin

North Carolina State University

Pennsylvania State University

Texas A\&M University

University of Massachusetts - Lowell

University of Wisconsin

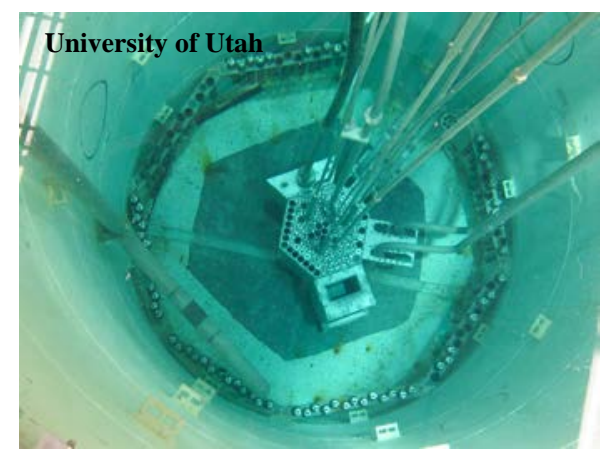

Power

$10 \mathrm{MW}$

$6 \mathrm{MW}$

2 MW

2 MW

1.25 MW

1 MW

1 MW

1 MW

1 MW

$1 \mathrm{MW} \& 5 \mathrm{~W}$

1 MW

1 MW
Facility

Washington State University

Ohio State University

Reed College

University of California - Irvine

University of Maryland

Missouri University of S\&T

University of Florida

University of Utah

Purdue University

Idaho State University

University of New Mexico

Rennselaer Polytechnic Institute
Power

1 MW

$500 \mathrm{~kW}$

$250 \mathrm{~kW}$

$250 \mathrm{~kW}$

$250 \mathrm{~kW}$

$200 \mathrm{~kW}$

$100 \mathrm{~kW}$

$100 \mathrm{~kW}$

$1 \mathbf{k W}$

$5 \mathrm{~W}$

$5 \mathrm{~W}$

$1 \mathrm{~W}$
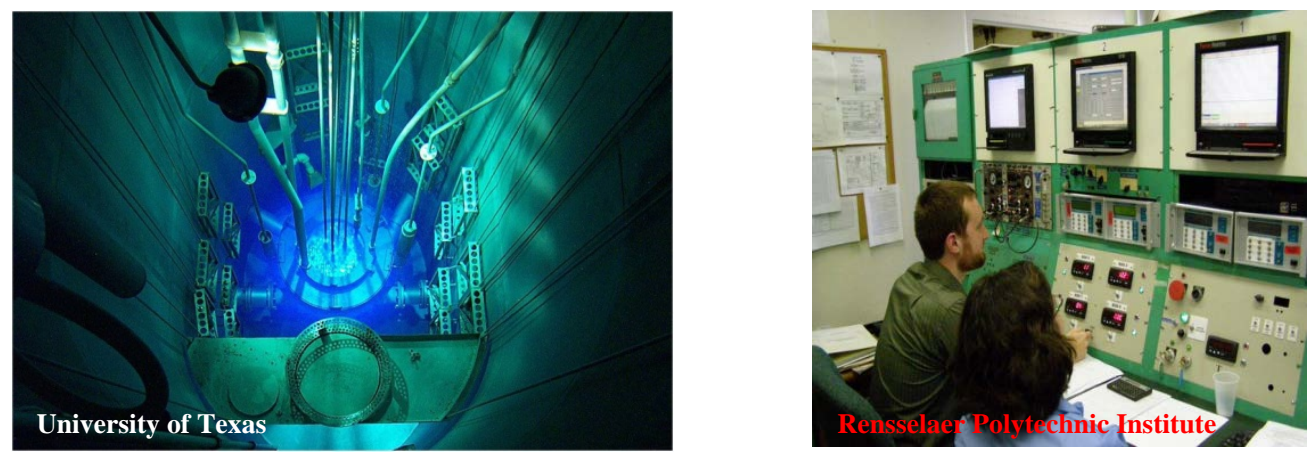


\section{Projected Fresh Fuel Needs}

\begin{tabular}{|l|c|c|}
\hline \multicolumn{1}{|c|}{ University } & Next Five Years & Lifetime of Core \\
\hline MURR & $\mathrm{X}$ & $\mathrm{X}$ \\
\hline MIT & $\mathrm{X}$ & $\mathrm{X}$ \\
\hline Rhode Island & $\mathrm{X}$ & $\mathrm{X}$ \\
\hline Kansas State University & $\mathrm{X}$ & $\mathrm{X}$ \\
\hline Penn State University & $\mathrm{X}$ & $\mathrm{X}$ \\
\hline Texas A\&M & $\mathrm{X}$ & $\mathrm{X}$ \\
\hline University of California at Davis & $\mathrm{X}$ & $\mathrm{X}$ \\
\hline University of Maryland & $\mathrm{X}$ & $\mathrm{X}$ \\
\hline University of Texas & $\mathrm{X}$ & $\mathrm{X}$ \\
\hline Washington State University & $\mathrm{X}$ & $\mathrm{X}$ \\
\hline Reed College & & $\mathrm{X}$ \\
\hline University of California at Irvine & & $\mathrm{X}$ \\
\hline
\end{tabular}




\section{Spent Nuclear Fuel}

- Spent Fuel Transfers to DOE Facilities

- Routine Shipments - MURR, MIT

- Other Shipments - Texas, Penn State, UC Davis

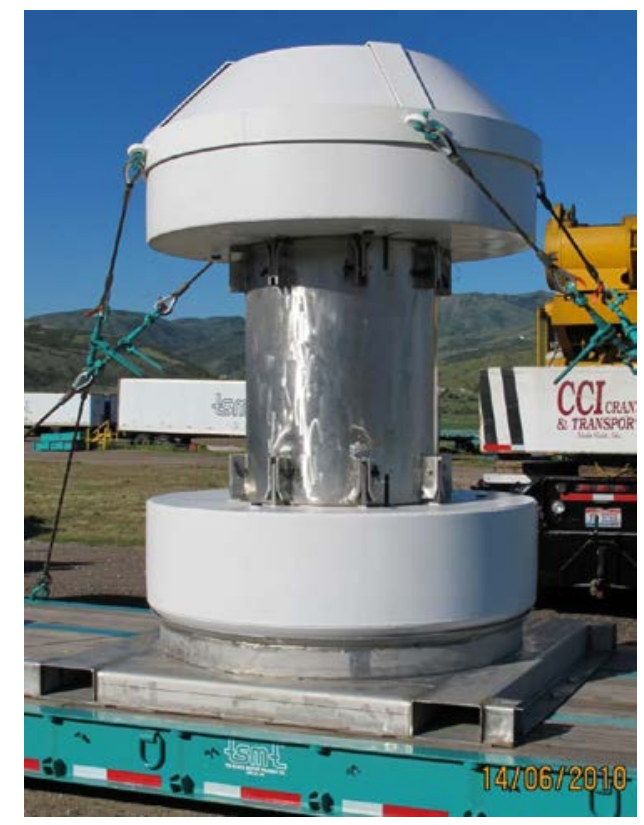




\section{Accomplishments}

- Provided fuel to maintain university reactors with sufficient fuel to operate at current power levels - MURR, MIT

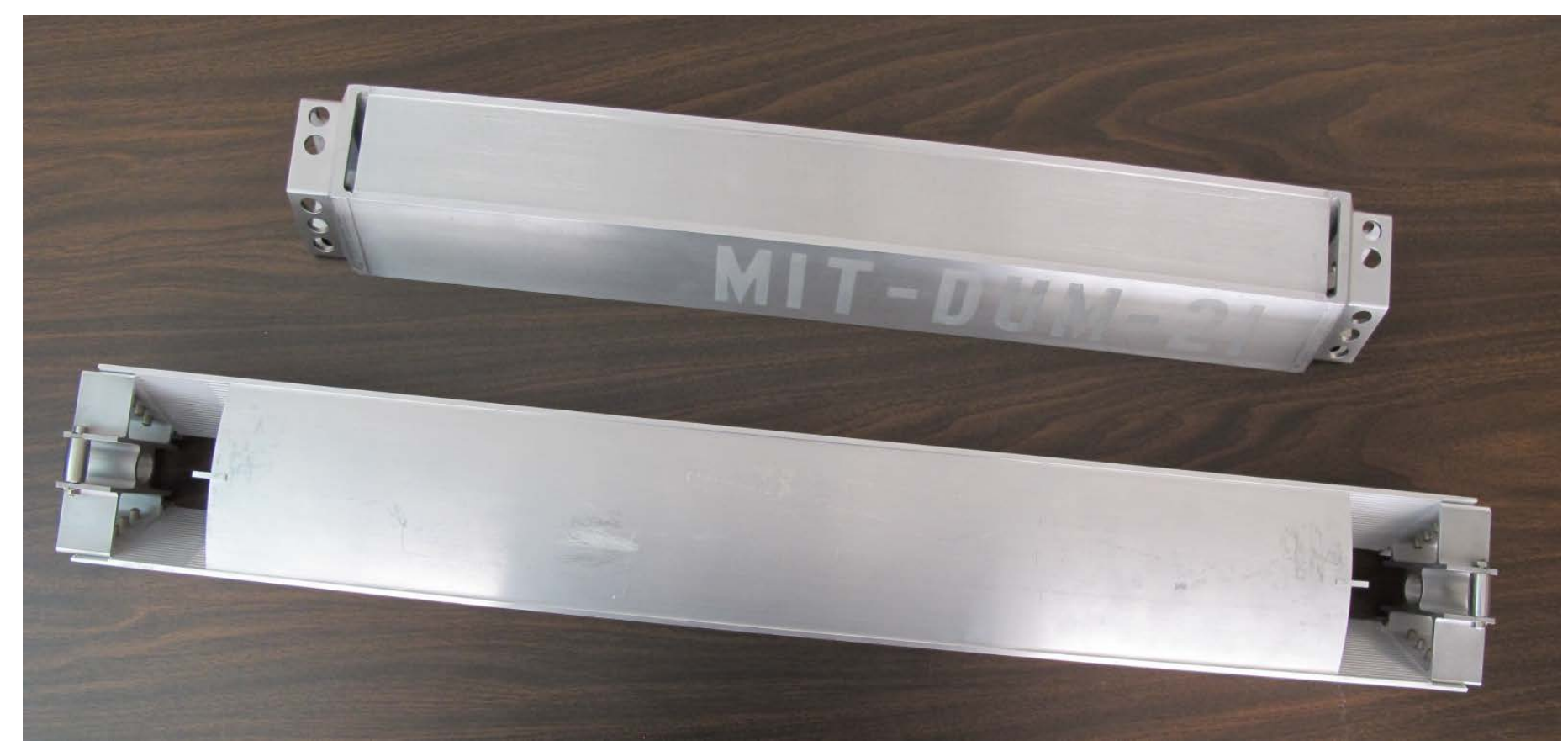




\section{Accomplishments}

- Shipped nineteen lightly irradiated TRIGA fuel elements from the Idaho National Laboratory to the University of Maryland
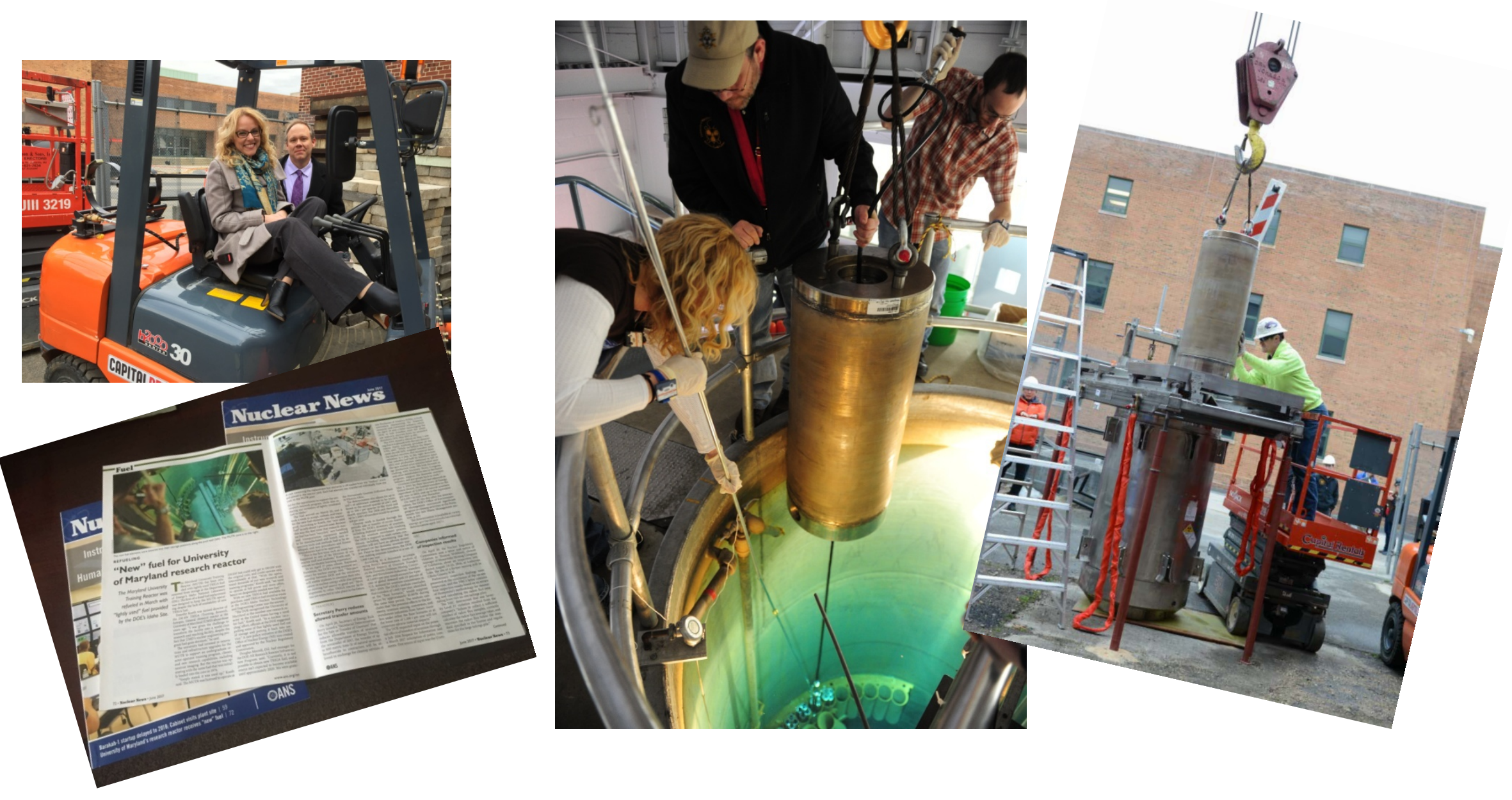


\section{Accomplishments}

- Three shipments of spent nuclear fuel from MURR to Savannah River Site receipt facility

- One shipment from MIT scheduled

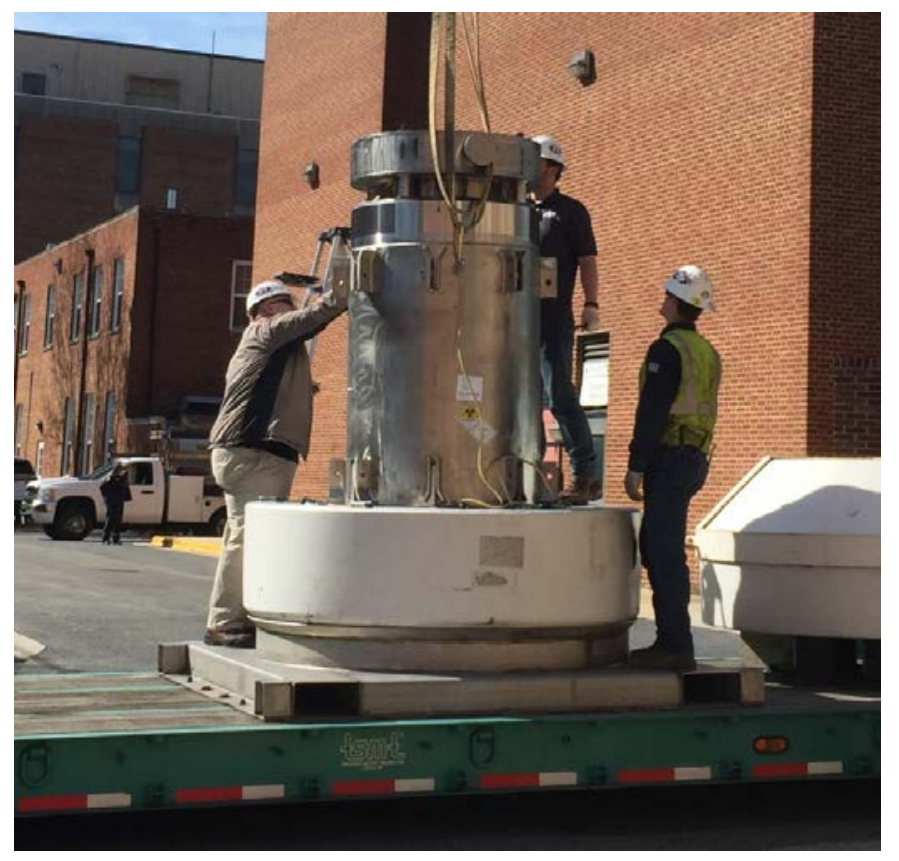




\section{Accomplishments}

- Assisting TRIGA International with the modifications and upgrades of the TRIGA fuel fabrication line

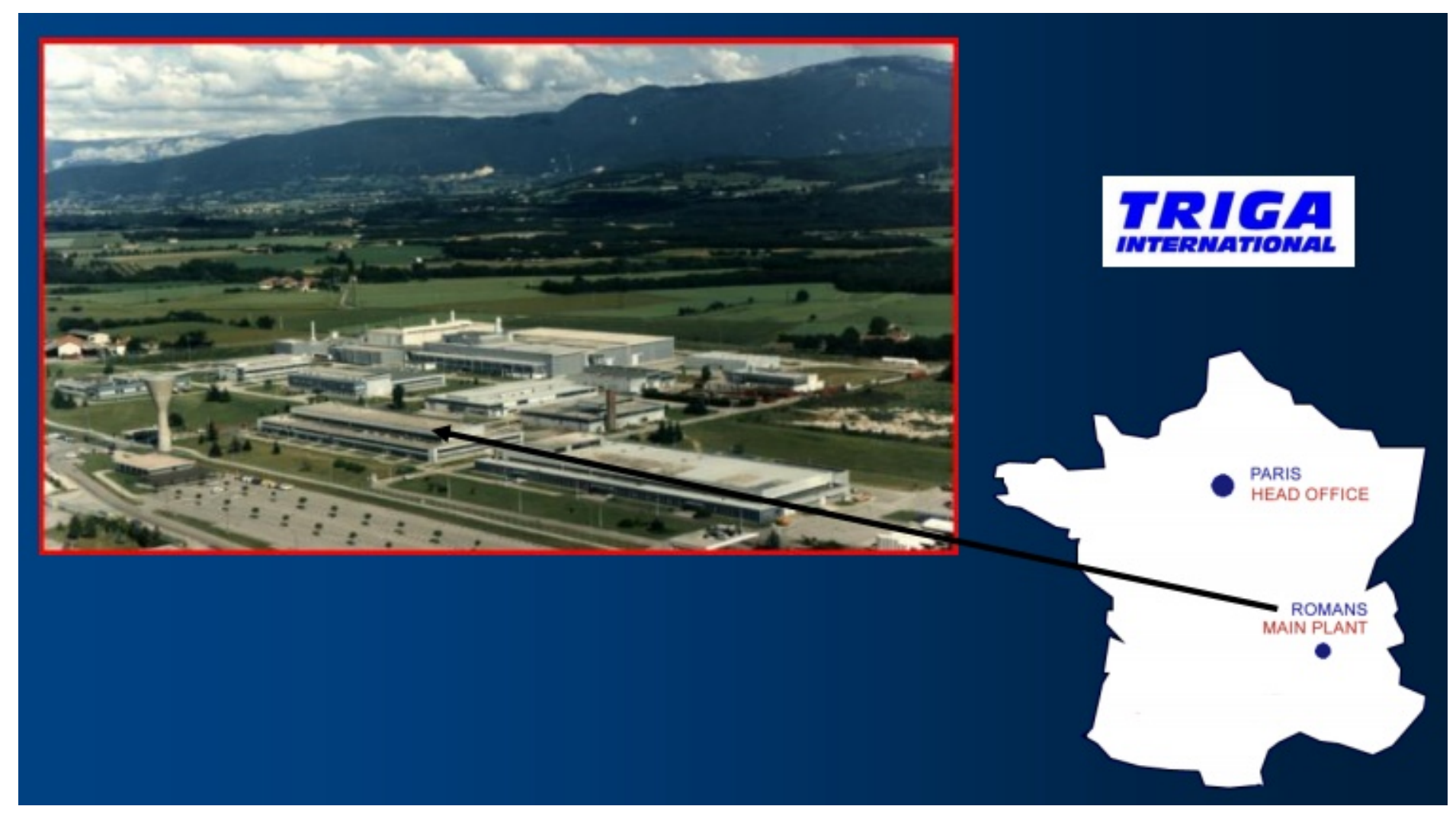




\section{Forecast}

- Research Reactor Infrastructure Program Annual Report

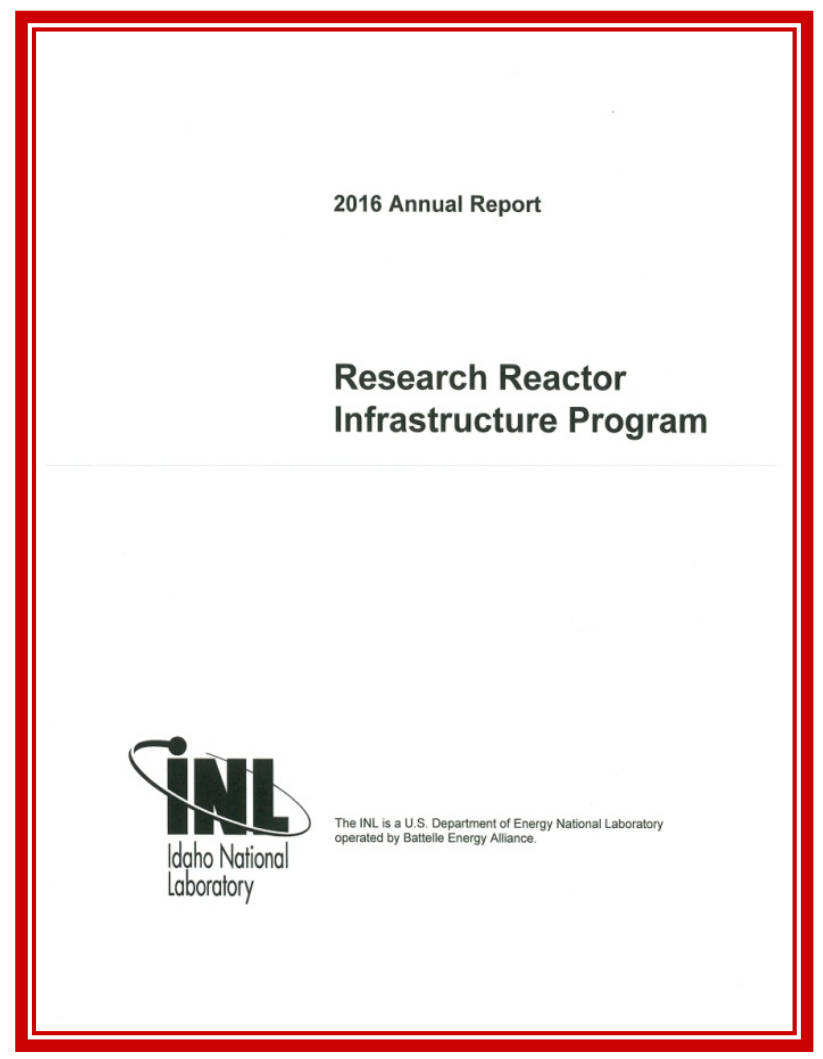




\section{Forecast}

- Provide fuel to maintain university reactors with sufficient fuel to operate at current power levels - MURR, MIT

- Provide 2,000 kilograms of Deuterium to MIT

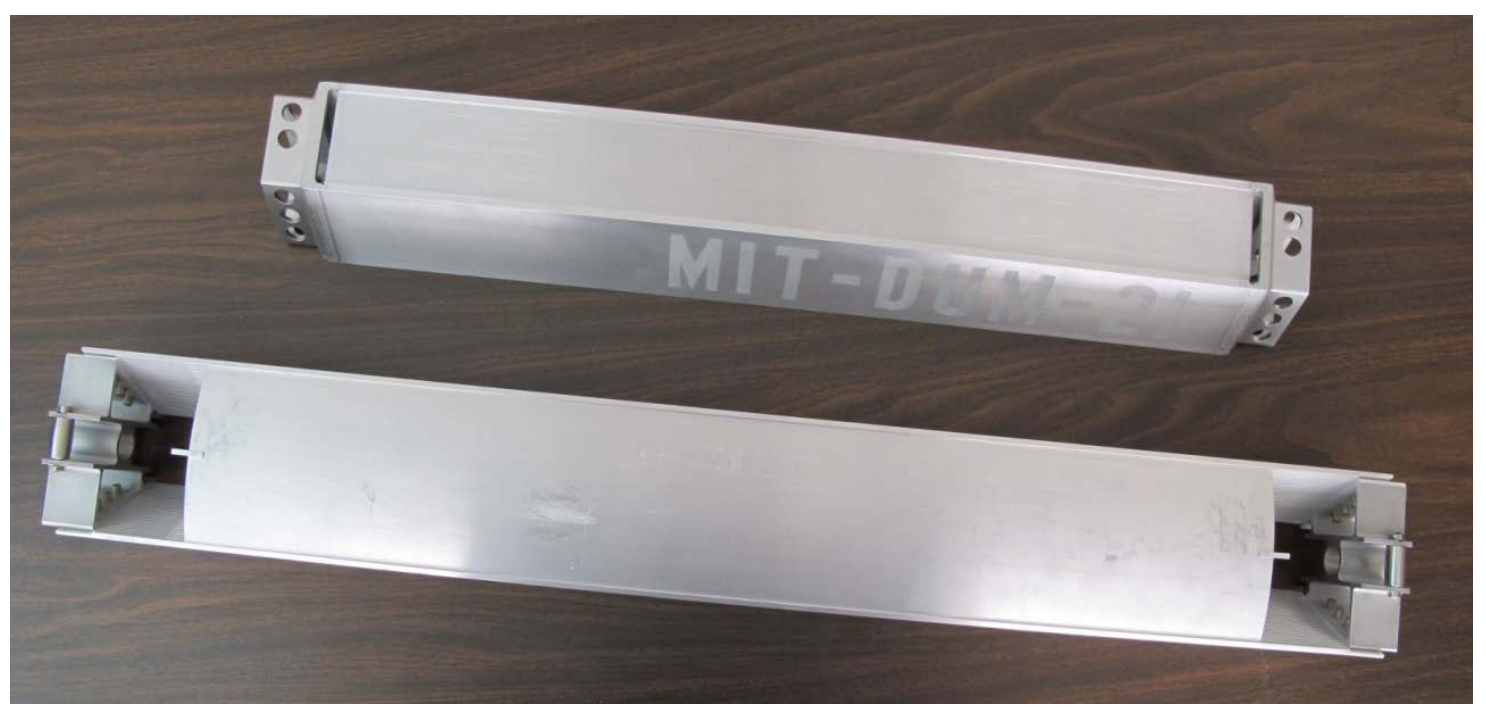




\section{Forecast}

- Complete four spent fuel shipments from MURR, MIT

- Complete shipment of spent Deuterium from MIT

- Prepare for one spent fuel shipment from Rhode Island (Shipment to be completed in FY-19)

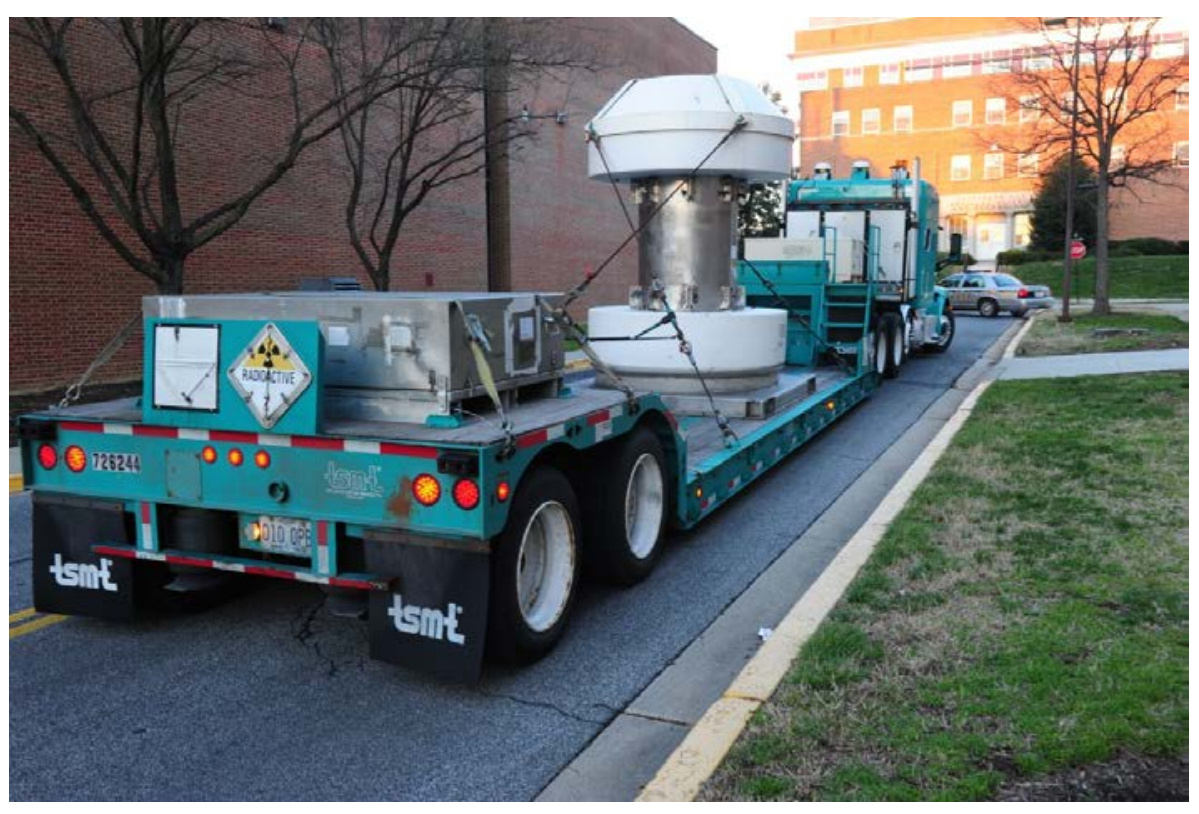




\section{Forecast}

- Complete a shipment of nineteen lightly irradiated TRIGA fuel from the Irradiated Fuel Storage Facility at the INL to a selected university reactor facility.
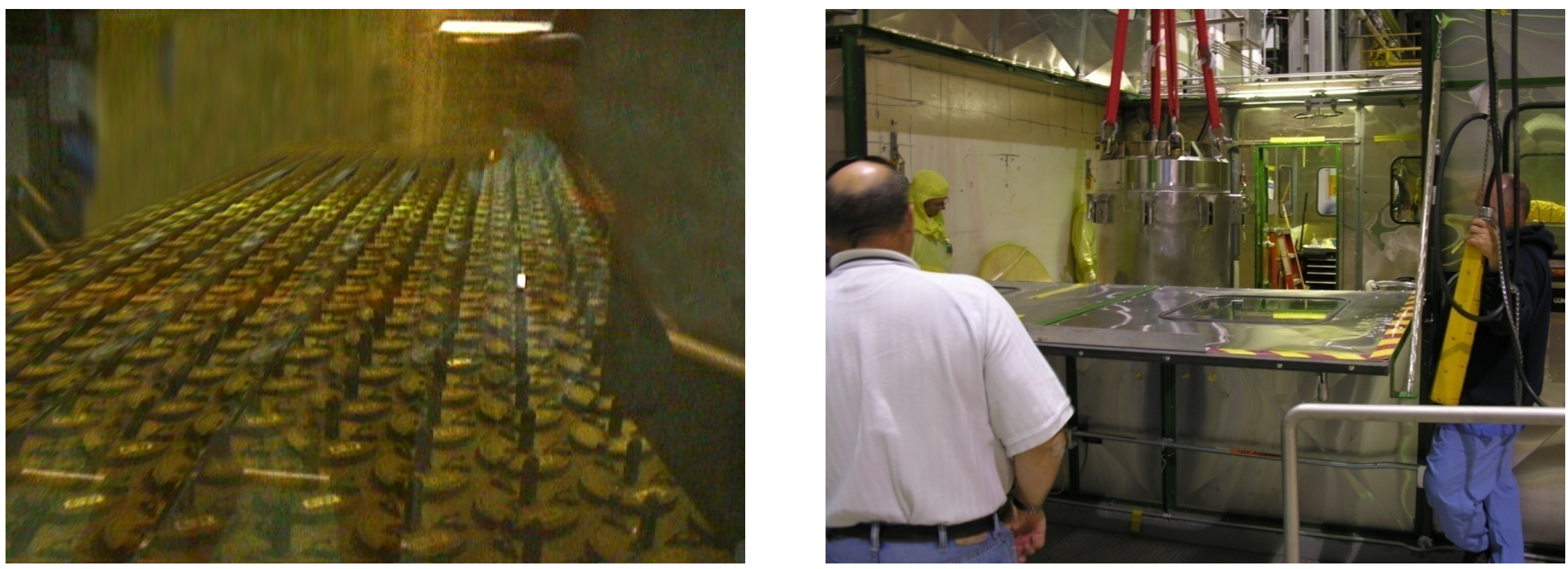


\section{$\underline{\text { Requests for Assistance }}$}

- Future requests for fresh fuel or spent fuel shipments need to be communicated to program office - Provide documentation to justify request (E-mail or official letter notification preferred)

- Other university concerns or assistance requests should be communicated to program for consideration as part of future budget planning activities. 


\section{Future Challenges}

- Fabrication and supply of TRIGA fuel elements

- Fabrication of fuel by TRIGA International

- Reallocation of fresh fuel inventory

- Reuse of lightly irradiated TRIGA fuel elements currently stored at the Irradiated Fuel Storage Facility at the Idaho National Laboratory (only standard $8.5 \mathrm{wt} \%$ fuel available)

- Receipt of additional Irradiated TRIGA fuel at the Irradiated Fuel Storage Facility

- Conversion of MURR and MIT from HEU to LEU fuel type 


\section{Idaho National Laboratory}

\section{Funding Profile}

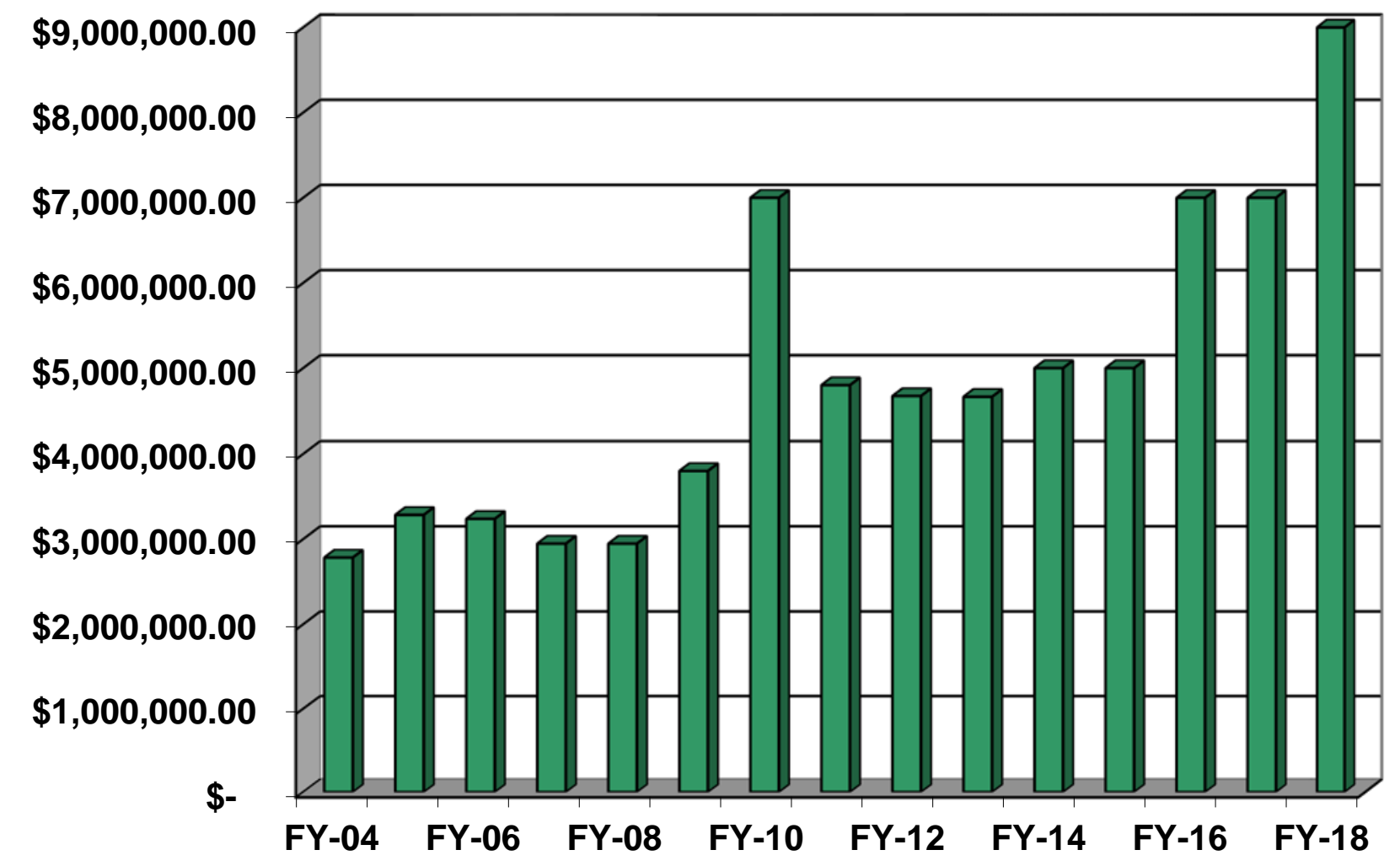




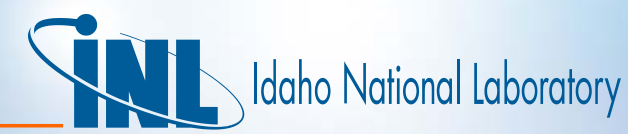

WASHINGTON STATE UNIVERSITY

\section{TRTR Team Members}

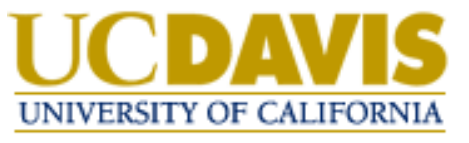

KANSAS STATE $\mid$ TRIGA mk II Nuclear U N I V E R S I T Y
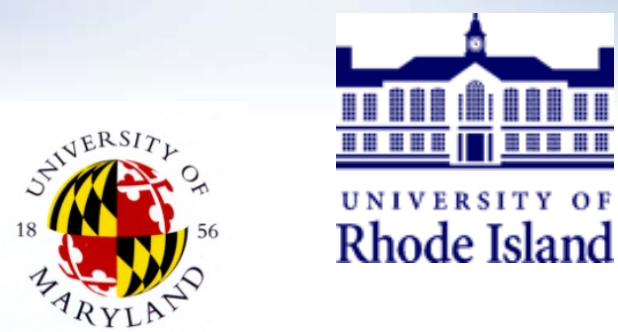
UNIVERSITY OF Rhode Island

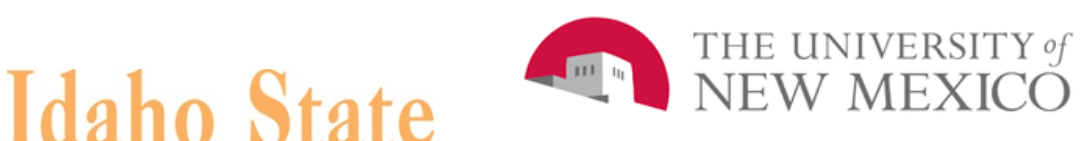

Iano Nitate

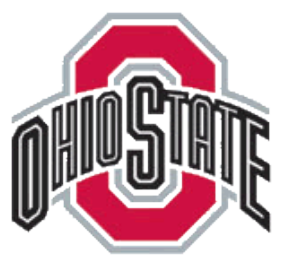

THE

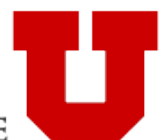

UNIVERSITY

OF UTAH

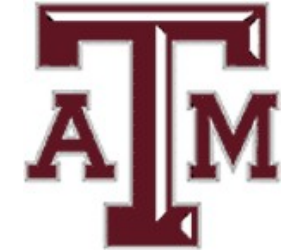

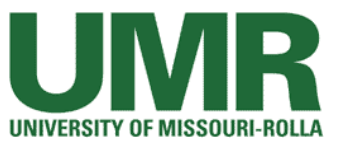

\section{REED COLTEGE}

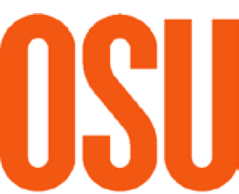

Oregon State

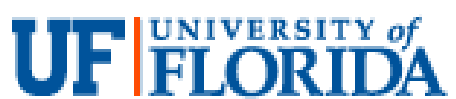

The Foundation for The Gator Nation

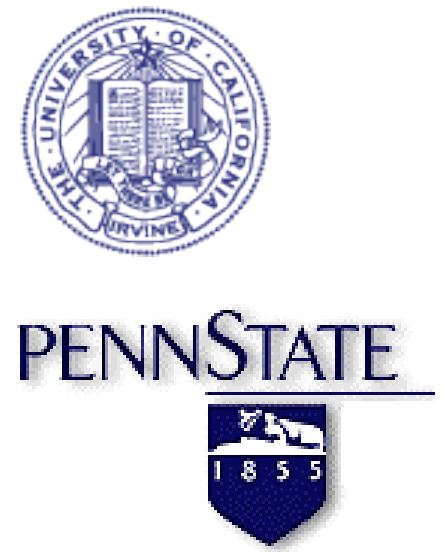

NC STATE UNIVERSITY

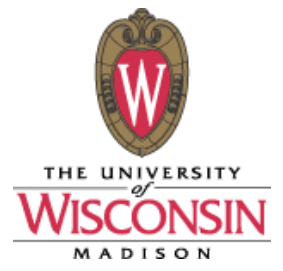
(ivensselaer
웅
University of Missouri-Columbia

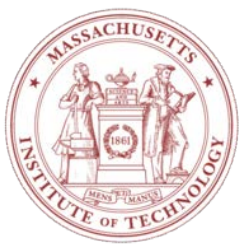




\section{TIIdaho National laboratory}

\section{Thank You!}

\section{Easy Questions?}




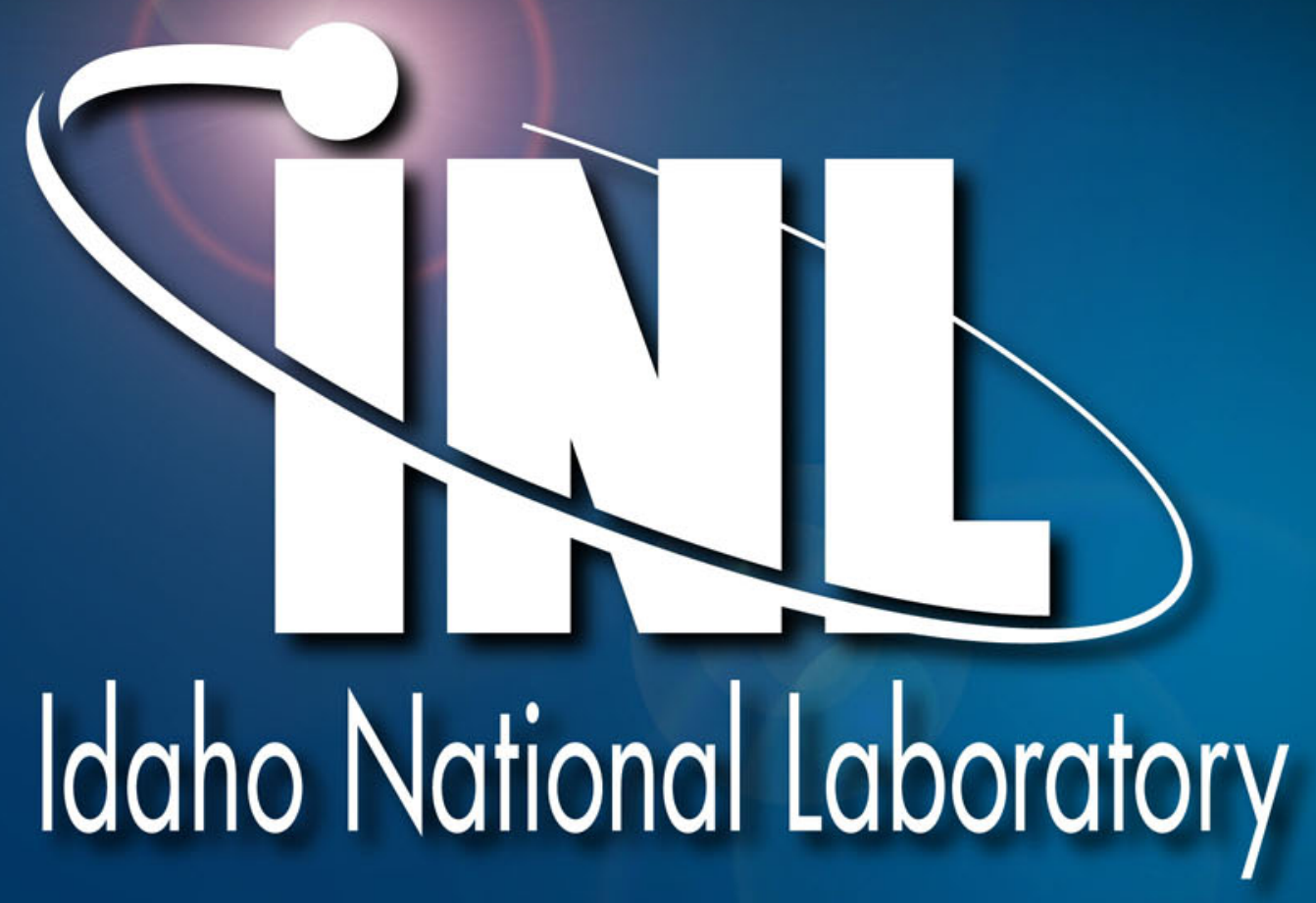

